\title{
NDRG4 promotes myogenesis via Akt/CREB activation
} \\ ${ }^{1}$ Key Laboratory of Swine Genetics and Breeding of Ministry of Agriculture \& Key Laboratory of Agriculture Animal Genetics, \\ Breeding and Reproduction of Ministry of Education, College of Animal Science and Technology, Huazhong Agricultural \\ University, Wuhan 430070, P.R. China \\ ${ }^{2}$ The Cooperative Innovation Center for Sustainable Pig Production, Wuhan 430070, China \\ ${ }^{3}$ College of Life Science and Agronomy, Zhoukou Normal University, Zhoukou 466000, China \\ *These authors have contributed equally to this work
}

Correspondence to: Bo Zuo, email: zuobo@mail.hzau.edu.cn

Keywords: myogenesis; NDRG4; CTMP; Akt; CREB

Received: July 28, $2017 \quad$ Accepted: September 03, $2017 \quad$ Published: October 06, 2017

Copyright: Zhu et al. This is an open-access article distributed under the terms of the Creative Commons Attribution License 3.0 (CC BY 3.0), which permits unrestricted use, distribution, and reproduction in any medium, provided the original author and source are credited.

\section{ABSTRACT}

N-Myc downstream-regulated gene 4 (NDRG4) plays an important role in biological processes and pathogenesis, but its function in muscle development is unclear. In this study, we investigated the function of the NDRG4 gene in the regulation of myogenic differentiation. NDRG4 expression is upregulated during muscle regeneration and $\mathrm{C} 2 \mathrm{C} 12$ myoblast differentiation. Gain and loss of function studies revealed that NDRG4 dramatically promotes expression of myogenic differentiation factor (MyoD), myogenin (MyoG), and myosin heavy chain (MyHC) genes and myotube formation. Mechanistically, the binding of NDRG4 to carboxylterminal modulator protein (CTMP) abates the interaction of CTMP and protein kinase $B$ (Akt) and increases the phosphorylation of Akt and CAMP response element binding protein (CREB), which leads to increased expression of myogenic genes. Our results reveal that NDRG4 promotes myogenic differentiation via Akt/CREB activation.

\section{INTRODUCTION}

Muscle formation is a well-orchestrated process in which pluripotent mesodermal cells give rise to myoblasts, subsequently proliferate, withdraw from the cell cycle, and differentiate into myotubes [1]. Myogenesis is precisely regulated by myogenic regulatory factors (MRFs) such as myogenic factor 5 (Myf5), MyoD, MyoG, and myogenic factor 6 (Myf6; also known as MRF4) [2, 3]. Myf5 and $M y o D$ are primary MRF proteins expressed at the myoblast stage and are essential for skeletal muscle lineage determination [4]. MyoD overexpression alone is sufficient to reprogram fibroblasts into muscle cells $[5,6]$. MyoG and $M y f 6$ are expressed upon differentiation of myoblasts into myotubes. Downregulation of $M y o G$ can even reverse terminal muscle cell differentiation [7]. The activity of such factors is under tight posttranslational control by signal transduction pathways, including the Akt pathway [8]. Akt is activated during myogenic differentiation in vitro [9], and Akt overexpression enhances myoblast differentiation [10]. Akt knockout inhibits myofiber formation [11]. CREB is the downstream molecule of Akt and plays important roles in the differentiation of muscle cells [12-15]. The Akt/CREB signaling pathway is critical for muscle development and involves multiple proteins and molecules.

NDRG4, also known as BDM1 and SMAP-8, is one of four members of the N-Myc downstreamregulated gene (NDRG) family, which is involved in cell proliferation, differentiation, development, and stress [16]. The NDRG family is highly conserved, and the identity between human and mouse NDRG4 is about $98 \%$. Previous studies showed that NDRG4 is highly expressed in the brain [17] and heart [18], and involved in brain and cardiac development [19, 20]. NDRG4 is downregulated in numerous cancer cell lines and tumor types, and functions as a tumor suppressor gene [21-23]. A recent study demonstrated that estrogen stimulated $N D R G 4$ expression and that NDRG4 expression levels are significantly upregulated at implantation sites during 
early pregnancy in mice. $N D R G 4$ plays critical roles in embryo implantation under the regulation of estrogen [24]. Previous gene expression omnibus (GEO) data (GDS586) show that NDRG4 is expressed in non-differentiated myoblasts and is suddenly upregulated during $\mathrm{C} 2 \mathrm{C} 12$ myogenic differentiation [25]. Furthermore, the GEO data (GDS4924) indicate that NDRG4 expression levels are low in uninjured tibialis anterior (TA) muscle and strongly upregulated at 3 and 7 days after muscle injury by cardiotoxin (CTX) or glycerol. Interestingly, this expression pattern is almost identical to those of the $M y o D$ and $M y o G$ genes [26], suggesting that NDRG4 may play a role in myogenic differentiation and skeletal muscle regeneration. Similar to NDRG4, MyoD, and MyoG activation, Akt and CREB are also activated during myogenic differentiation [8, 27] and skeletal muscle regeneration $[15,28]$. Besides, the Search Tool for the Retrieval of Interacting Genes (STRING) is used to evaluate the relationship between $N D R G 4$ and Akt signaling pathway, and the result shows that NDRG4 is a gene in the Akt Signaling SuperPath. However, the effects of NDRG4 on myoblast differentiation and the relationship between NDRG4 and the Akt/CREB signaling pathway are unclear.

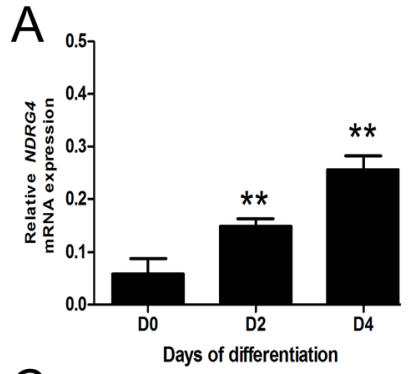

C
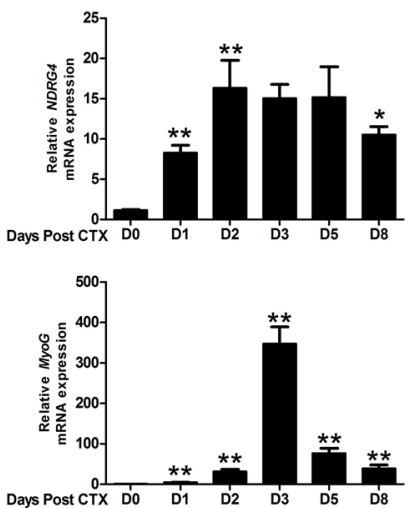

In the present study, we investigated the function of the NDRG4 gene in the regulation of $\mathrm{C} 2 \mathrm{C} 12$ myogenic differentiation. Treatment of $\mathrm{C} 2 \mathrm{C} 12$ myoblasts with NDRG4 activated the Akt/CREB signaling pathway and increased expression of the $M y o D$ and $M y o G$ genes, resulting in promotion of myoblast differentiation. Our findings define a novel function of the NDRG4 gene in skeletal muscle development and suggest a molecular mechanism by which NDRG4 promotes myogenic differentiation.

\section{RESULTS}

\section{The $N D R G 4$ gene is upregulated during myogenic differentiation and skeletal muscle regeneration}

To investigate the role of NDRG4 in myoblast differentiation, qRT-PCR and Western blotting were used to determine the expression pattern of the NDRG4 gene during $\mathrm{C} 2 \mathrm{C} 12$ myoblast differentiation. The qRTPCR results showed that expression of $N D R G 4$ increased gradually and significantly as $\mathrm{C} 2 \mathrm{C} 12$ cells differentiated (Figure 1A). Western blotting results indicated that
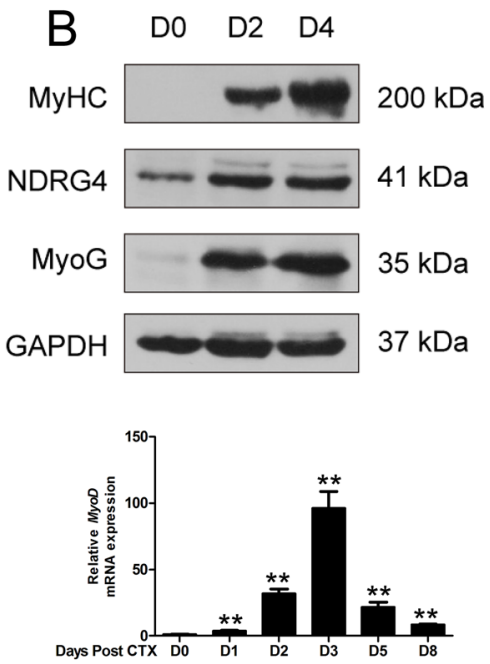

Figure 1: N-Myc downstream-regulated gene 4 (NDRG4) expression levels are increased during myoblast differentiation and muscle regeneration. (A) qRT-PCR analysis of the expression of $N D R G 4$ in $\mathrm{C} 2 \mathrm{C} 12$ cells at days 0,2 , and 4 after differentiation. (B) Western blot analysis of the NDRG4 protein in $\mathrm{C} 2 \mathrm{C} 12$ cells at days 0,2 , and 4 after differentiation. Myogenin (MyoG) and MyHC are two marker genes of muscle differentiation. (C) qRT-PCR results showing the expression of the NDRG4, myogenic differentiation factor $(M y o D)$, and $M y o G$ genes during muscle regeneration. Hindlimb muscle was subjected to cardiotoxin (CTX) injection and harvested on the indicated days after injury for RNA analysis. GAPDH was used as an internal control. Values were normalized to GAPDH. Data are presented as means \pm standard error of the mean $(\mathrm{n}=3)$. Asterisks above columns represent significant differences among groups $\left({ }^{* *} P<\right.$ 0.01 ). 
the NDRG4 protein was detected in proliferating myoblasts and that expression increased during myogenic differentiation, while the protein expression levels of two myogenic marker genes (MyoG and $\mathrm{MyHC}$ ) increased greatly during myogenic differentiation of $\mathrm{C} 2 \mathrm{C} 12$ cells (Figure 1B). As myogenic differentiation is an important event during skeletal muscle regeneration, we investigated the change in NDRG4 mRNA expression following CTX-mediated injury of mouse skeletal muscle. NDRG4 expression levels were low in uninjured hindlimb muscle and increased rapidly at 2 and 5 days after muscle injury by CTX. In this period, expression of both MyoD and $\mathrm{MyoG}$ also increased dramatically. Additionally, expression of NDRG4 peaked earlier than that of MyoD and MyoG (Figure 1C). Together, these results suggest that NDRG4 may be involved in myogenesis and muscle regeneration.

\section{The NDRG4 gene had no effect on myoblast proliferation}

As the NDRG4 gene regulates the proliferation of cancer-associated cells, we performed gain- and loss-of-function studies to examine whether NDRG4 has the same roles in myoblast proliferation. $\mathrm{C} 2 \mathrm{C} 12$ cells were transfected with the pcDNA3.1-NDRG4 or pcDNA3.1 plasmid and pooled siNDRG4 or negative control (NC). When the cell index reached about 1.0, cell growth dynamics were continuously monitored by an xCELLigence system and the cell cycle was examined by flow cytometry. No significant differences in cell growth rates or the cell cycle were observed between the treated cells and the control (Figure 2A and 2B). These observations indicated that NDRG4 had no effect on the proliferation of $\mathrm{C} 2 \mathrm{C} 12$ cells.

\section{Knockdown of NDRG4 inhibits myogenic differentiation}

Since NDRG4 expression was increased during myogenesis and the expression of the NDRG4 protein was positively correlated with the levels of myogenic markers (MyoG, MyHC) during myogenic differentiation, as mentioned above, we speculated that NDRG4 may have a positive role in $\mathrm{C} 2 \mathrm{C} 12$ cell differentiation. To test this hypothesis, loss-of-function studies were performed. The cells were lysed at 0,2 , and 4 days after cell differentiation. The results demonstrated that NDRG4 siRNA significantly inhibited the protein expression of NDRG4 at day 0 (D0), day 2 (D2), and day 4 (D4) post transfection. Meanwhile, the expression levels of MyoD, MyoG, and MyHC were significantly suppressed (Figure 3A and 3B). The immunofluorescence of MyHC was used to examine myotube formation in $\mathrm{C} 2 \mathrm{C} 12$ cells 5 days after transfection. MyHC-positive cells were scored as mononucleate, containing two to five nuclei, or containing six or more nuclei. NDRG4 knockdown cells formed smaller myotubes with more mononucleate cells (54\%) compared to control cells $(31 \%)$. In contrast, the percentage of myotubes containing cells with two to five nuclei and six or more nuclei decreased to $32 \%$ and $14 \%$, compared to $45 \%$ and $24 \%$ of control cells, respectively (Figure 3C and 3D). These results clearly demonstrate that NDRG4 knockdown inhibited myoblast differentiation in vitro.

\section{Overexpression of NDRG4 enhances myogenic differentiation}

To confirm the above results, $\mathrm{C} 2 \mathrm{C} 12$ myoblasts were transfected with control or NDRG4 expression vectors and induced to differentiate. Total protein was extracted at D0, D2, and D4. The expression level of NDRG4 was significantly increased with overexpression, and the expression of myogenic marker genes, including MyoD, MyoG, and MyHC, was significantly enhanced in NDRG4overexpressing $\mathrm{C} 2 \mathrm{C} 12$ myoblasts compared to the control (Figure 4A and 4B). Next, we examined the effect of NDRG4 overexpression on myotube formation. Control and NDRG4-overexpressing C2C12 cells were induced to differentiate for 3 days and stained with anti-MyHC antibody followed by 4',6-diamidino-2-phenylindole (DAPI) staining. NDRG4-overexpressing C2C12 cells formed larger and more numerous myotubes than control (pcDNA3.1) cells (Figure 4C and 4D). These data suggest that NDRG4 promotes myoblast differentiation.

\section{NDRG4 activates the Akt/CREB pathway in myoblast differentiation}

To determine the molecular pathways by which NDRG4 mediates myogenic differentiation, we selected Akt as a candidate for further analysis, as it is a wellknown mediator of cell survival $[29,30]$ and a key regulator of myogenic differentiation [8] and muscle mass [31]. First, we analyzed Akt phosphorylation in myogenesis, and found that the phosphorylation level gradually increased during myoblast differentiation, which was similar to the expression pattern of NDRG4 (Figure 5A). Next, we examined whether the Akt signaling pathway is involved in NDRG4 regulated myogenesis. As expected, significant decreases in phosphorylated Akt expression were observed in NDRG4 knockdown $\mathrm{C} 2 \mathrm{C} 12$ cells compared with the control (Figure 5B and 5C, upper), while NDRG4 overexpression had the opposite effect (Figure 5D and 5E, upper). Taken together, these results suggest that NDRG4 participates in Akt-mediated myogenic differentiation. Second, CREB was chosen for further study, as it is a key regulatory target of Akt and closely associated with myogenesis. Overexpression of NDRG4 enhanced CREB activation as determined by an increase in CREB phosphorylation at Ser133, but did 
not significantly alter the expression of CREB (Figure 5D and 5E, lower). NDRG4 knockdown had the inverse effect (Figure 5B and 5C, lower), confirming the results of the overexpression experiment. These results suggest that NDRG4 promotes $\mathrm{C} 2 \mathrm{C} 12$ myogenic differentiation by activating the Akt/CREB signaling pathway.

\section{NDRG4 and CTMP physically interact in differentiating myoblasts and the interaction mediates the activity of Akt}

To investigate further the mechanism by which NDRG4 enhances the phosphorylation levels of Akt, we attempted to identify the Akt-interacting proteins phosphatase and tensin homolog (PTEN) and CTMP. Akt phosphorylation is negatively regulated by PTEN [32], which contributes to cell growth and proliferation. CTMP is an Akt-binding protein and suppresses Akt activity by inhibiting Akt phosphorylation [33]. Western blotting was performed to determine expression of PTEN and CTMP after NDRG4 knockdown, but no significant differences in expression were found (Figure 6A and 6B). Previous studies have shown that NDRG4 can recruit some proteins to play biological functions [34, 35]. Thus, we examined whether there was any physical interaction between NDRG4 and PTEN or CTMP in $\mathrm{C} 2 \mathrm{C} 12$ cells. $\mathrm{C} 2 \mathrm{C} 12$ cells were induced to differentiate and the lysates were immunoprecipitated with control
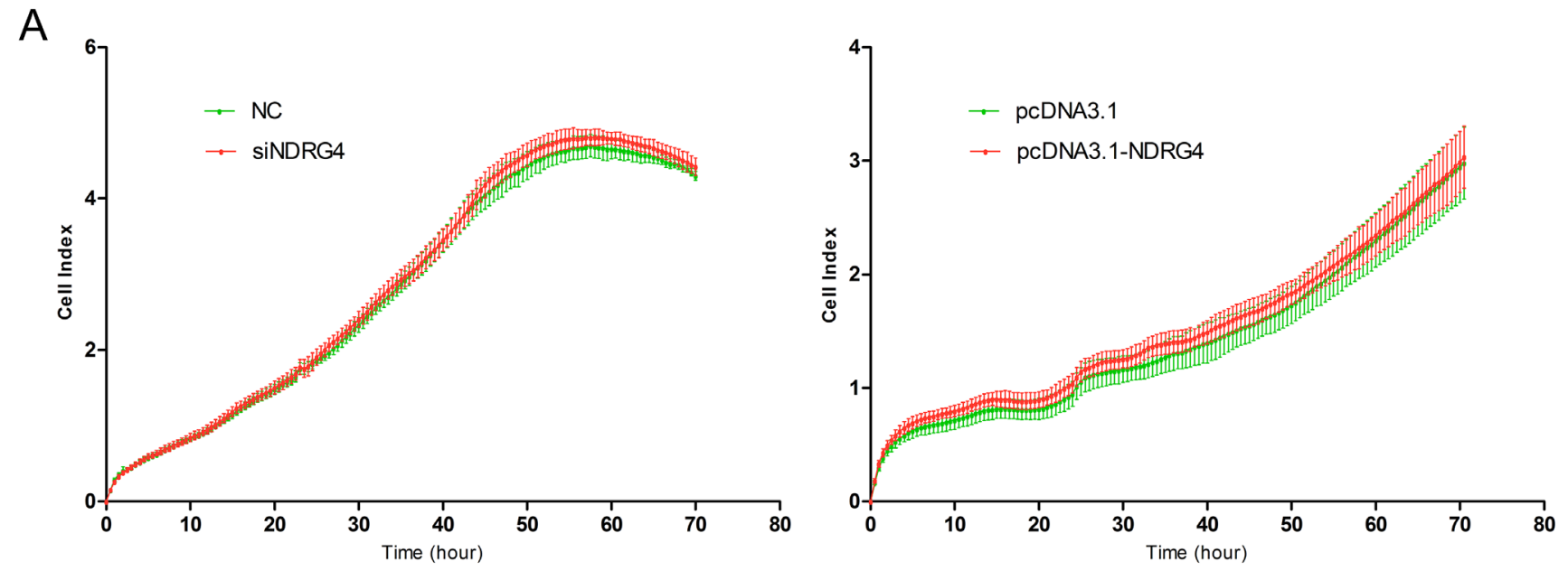

B
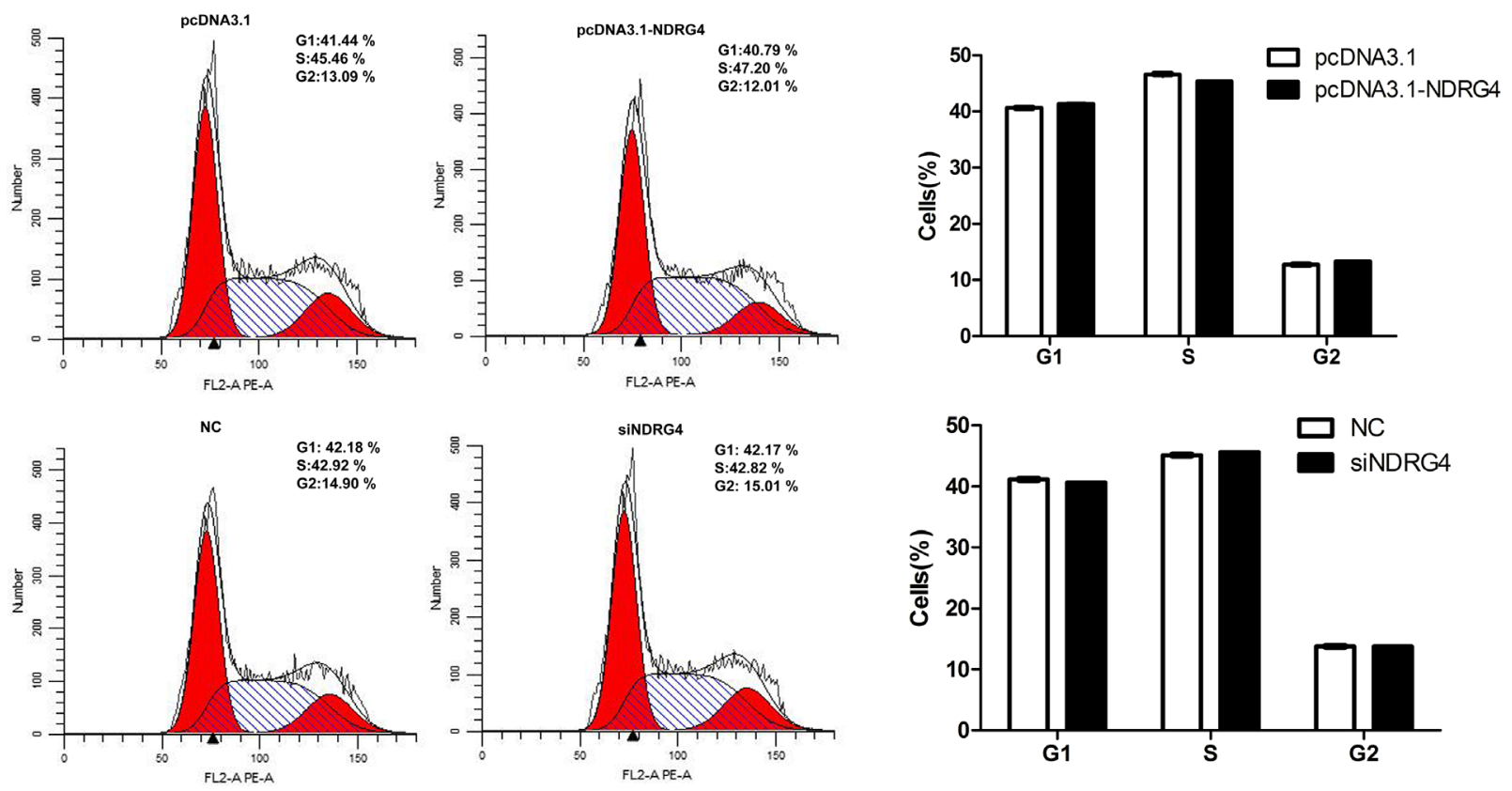

Figure 2: NDRG4 has no effect on myoblast proliferation. C2C12 cells were transfected with pcDNA3.1-NDRG4 or pcDNA3.1 and small interfering RNA against NDRG4 (siNDRG4) or negative control (NC). (A) Cell growth dynamics were continuously monitored by the xCELLigence system. (B) Cell cycle phase was analyzed $48 \mathrm{~h}$ after transfection by propidium iodide flow cytometry. 

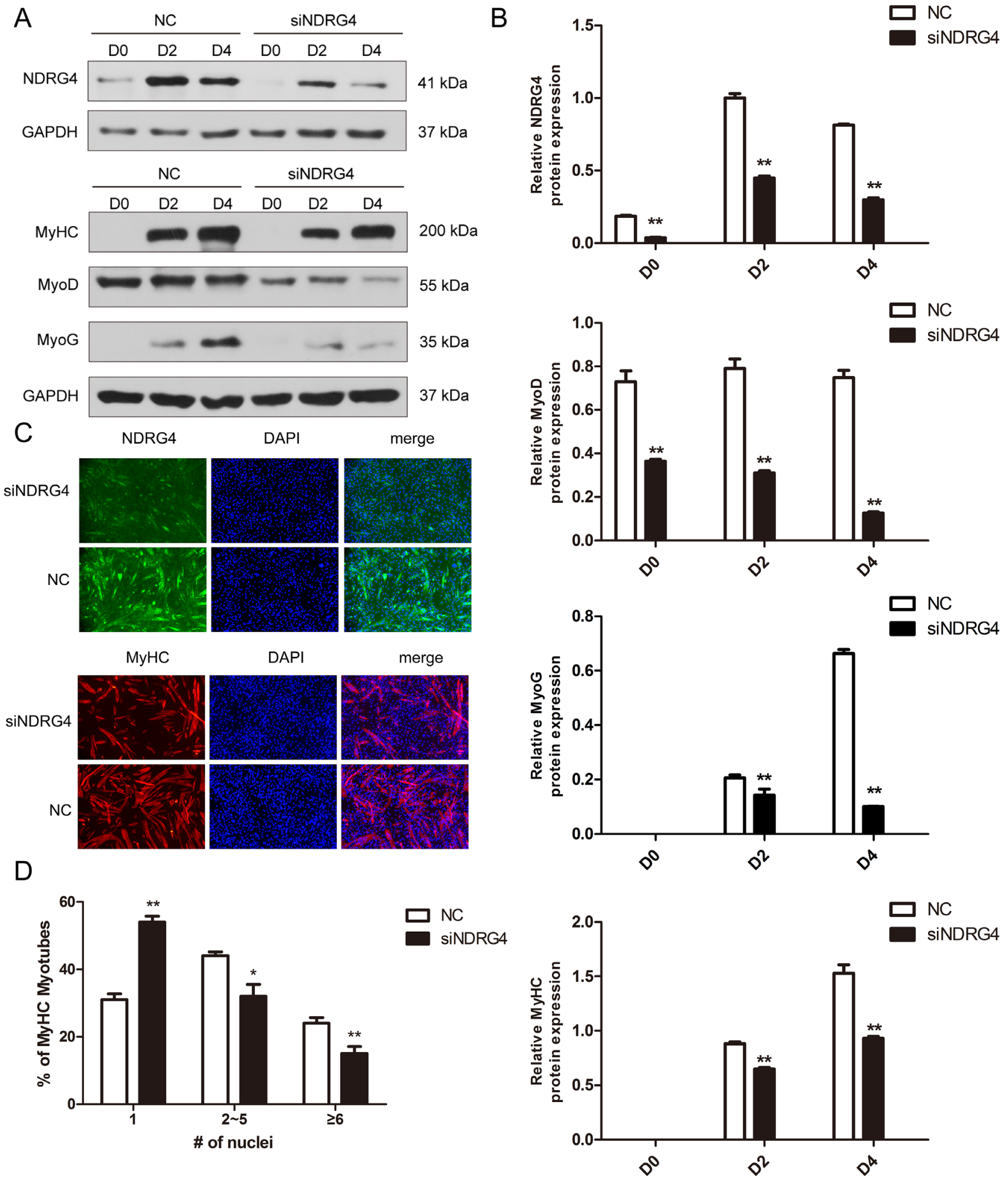

Figure 3: Knockdown of NDRG4 inhibits myogenic differentiation. (A) Western blot results of NDRG4, MyoD, MyoG, and MyHC protein expression levels after NDRG4 knockdown at 0 days (D0), 2 days (D2), and 4 days (D4). (B) Relative protein expression levels represented by the ratio of detected protein to the GAPDH protein expression level after NDRG4 knockdown at D0, D2, and D4. The quantifications of Western blot data are presented as means \pm standard deviation (SD; $n=3)$. (C) Immunofluorescence results of NDRG4 and MyHC protein expression levels after NDRG4 knockdown. Transfected C2C12 myoblasts were differentiated for 5 days, and stained with anti-NDRG4 (green) and anti-MyHC antibodies (red), and 4',6-diamidino-2-phenylindole (DAPI; blue), and imaged by fluorescence microscopy. Bars, $200 \mu \mathrm{m}$. (D) The quantification of myotube formation is shown in the panel. 
IgG or NDRG4 antibodies followed by immunoblotting with PTEN and CTMP antibodies, only CTMP strongly co-immunoprecipitated with NDRG4 (Figure 6C). Immunofluorescence confocal microscopic analysis was employed to determine the subcellular location of NDRG4 and CTMP in C2C12 cells. The results revealed that NDRG4 co-localized with CTMP in the cytoplasm
(Figure 6D). These findings suggest that NDRG4 interacts with CTMP under basal conditions. It was reported that binding of CTMP to pAkt reduces Akt activity by inhibiting phosphorylation of serine 473 and threonine 308. We next investigated whether NDRG4 affected the binding of CTMP to pAkt during myogenic differentiation. We found that knockdown of NDRG4 decreased the
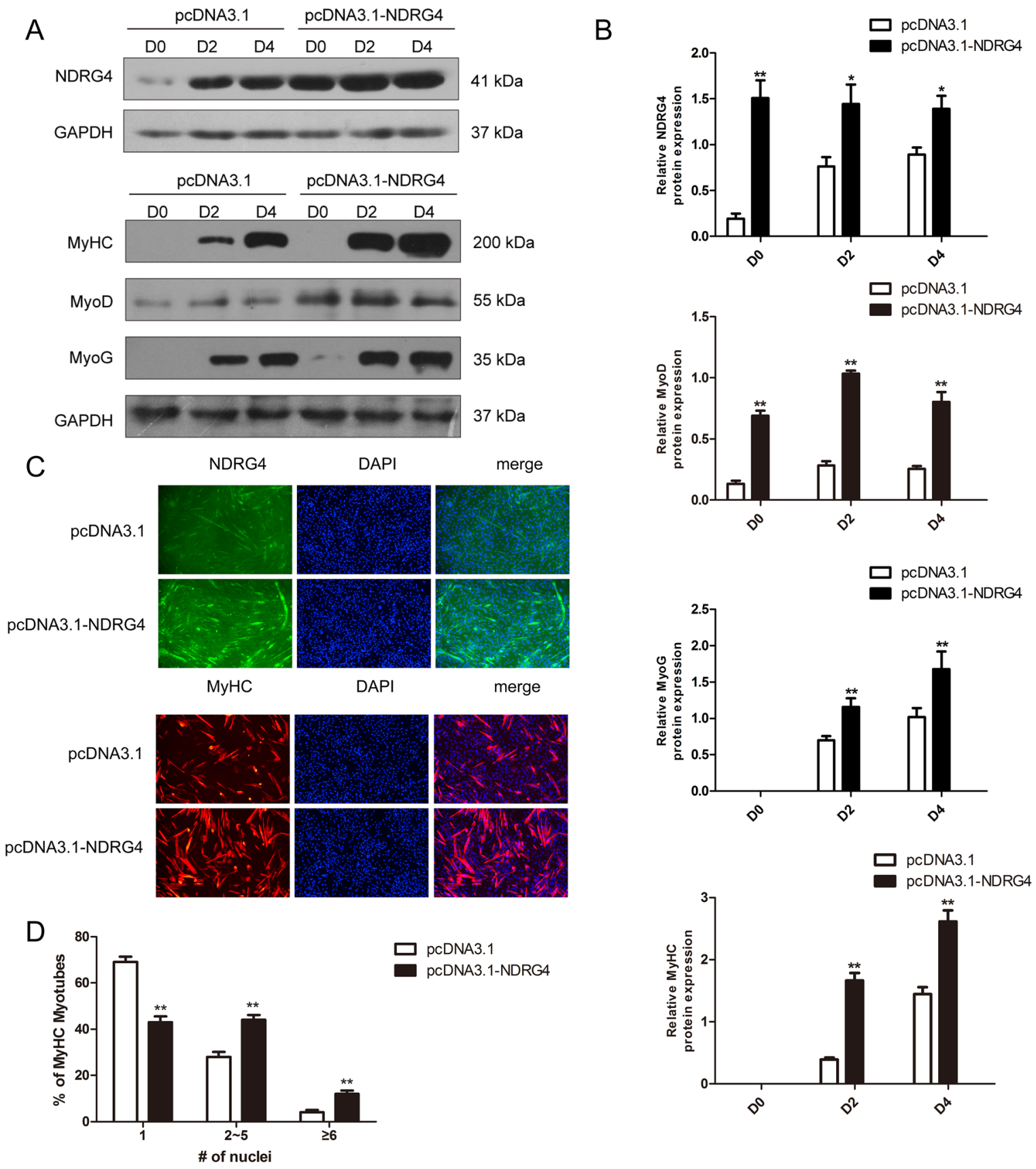

Figure 4: Overexpression of NDRG4 enhances myogenic differentiation. (A) Western blot results of NDRG4, MyoD, MyoG, and MyHC protein expression levels after NDRG4 overexpression at D0, D2, and D4. (B) Relative protein expression levels represented by the ratio of detected protein to GAPDH protein expression level after NDRG4 overexpression at D0, D2, and D4. (C) Immunofluorescence results of NDRG4 and MyHC protein expression levels after NDRG4 overexpression. Transfected C2C12 myoblasts were differentiated for 3 days, stained with anti-NDRG4 (green) and anti-MyHC antibodies (red), and DAPI (blue), and imaged by fluorescence microscopy. Bars, $200 \mu \mathrm{m}$. (D) The quantification of myotube formation is shown in the panel. 
A
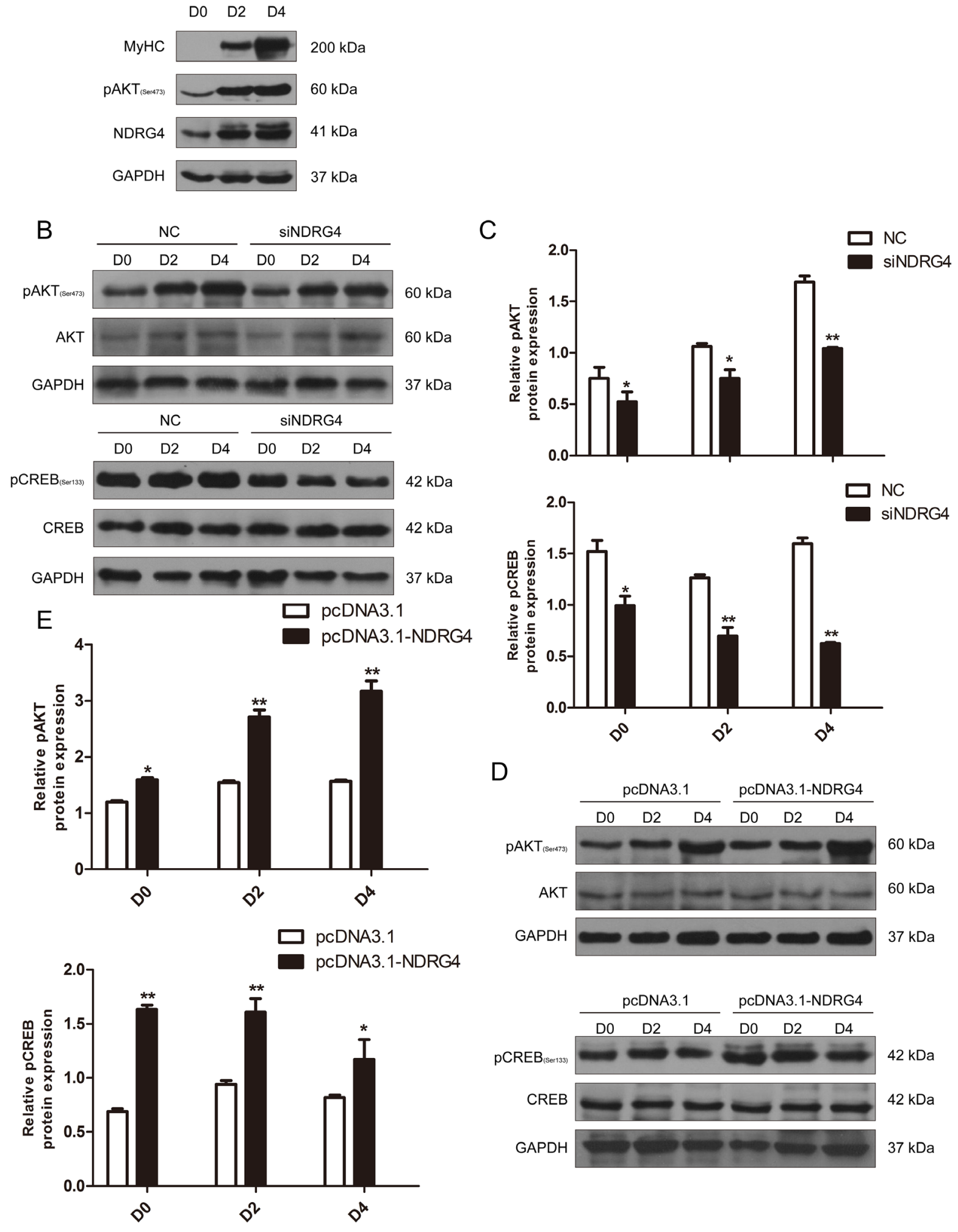

Figure 5: NDRG4 activates the Akt/CREB pathway during myoblast differentiation. (A) Western blot results of NDRG4 and pAkt protein expression levels in $\mathrm{C} 2 \mathrm{C} 12$ cells at differentiation days 0,2, and 4. MyoG and $\mathrm{MyHC}$ are two known markers of muscle differentiation. (B) Western blot results of pAkt, Akt, pCREB, and CREB protein expression levels in $\mathrm{C} 2 \mathrm{C} 12$ cells transfected with siNDRG4. (C) Relative protein expression levels of pAkt and pCREB after NDRG4 knockdown in C2C12 cells at D0, D2, and D4. (D) Western blot results showing the changes in pAkt, Akt, pCREB, and CREB protein expression levels in $\mathrm{C} 2 \mathrm{C} 12$ cells transfected with NDRG4 plasmids. (E) Relative protein levels of pAkt and pCREB after NDRG4 overexpression at D0, D2, and D4. ${ }^{*} P<0.05 ;{ }^{* *} P<0.01$. 
interaction between NDRG4 and CTMP during C2C12 differentiation compared to that of control cells, while the binding capacity of CTMP to pAkt increased (Figure 6E). Simultaneously, NDRG4 knockdown decreased expression of phosphorylated Akt in C2C12 cells (Figure 5B). Collectively, these observations indicate that NDRG4 and CTMP physically interact in differentiating myoblasts, and this interaction increases the phosphorylation of Akt.

\section{NDRG4 promotes myogenesis by improving CREB transcription activity}

To confirm that NDRG4 promotes myogenesis through CREB, pcDNA3.1-NDRG4 and siCREB were co-transfected in $\mathrm{C} 2 \mathrm{C} 12$ myoblasts. Overexpression of NDRG4 promoted MyoG and MyHC protein expression. After transfection with CREB siRNA fragments, overexpression of NDRG4 did not increase the protein expression of MyoG and MyHC compared with the control (Figure 7A and 7B). To detect whether NDRG4 was involved in CREB phosphorylation-mediated myogenesis, we used the phosphorylation inhibitor H89 to decrease the CREB phosphorylation level [36, 37], after overexpression of NDRG4. The results are similar to those of the RNA interference experiments, nevertheless, it did not significantly alter the expression of CREB (Figure 7C and 7D). Therefore, the effect of NDRG4 on myogenesis was dependent on CREB protein
A

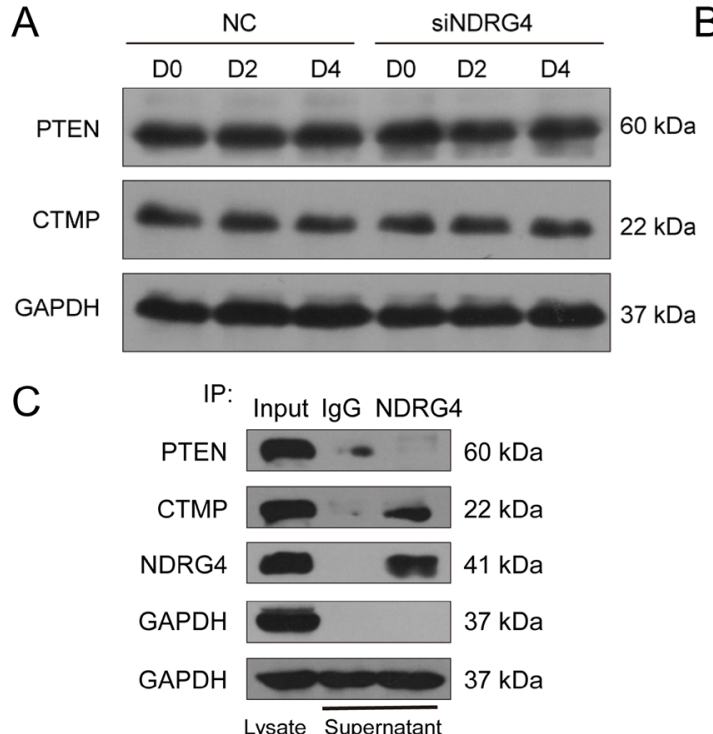

D

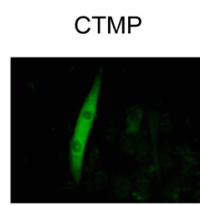

NDRG4
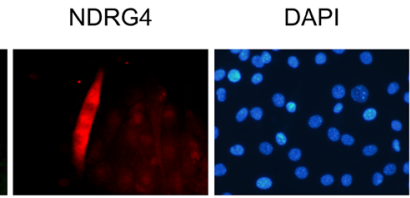

E
B
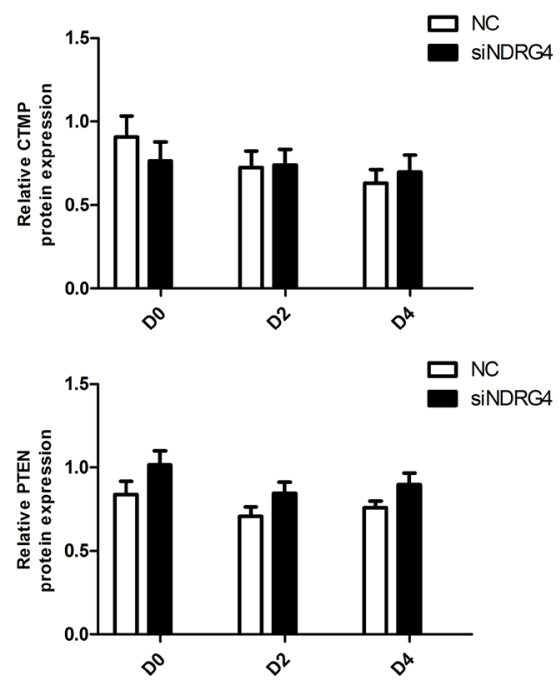

merge

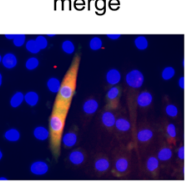

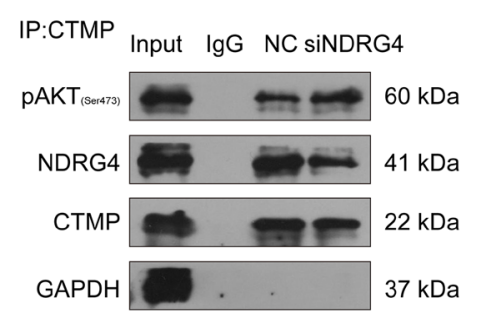

Figure 6: NDRG4 and CTMP physically interact in differentiating myoblasts and this interaction mediates Akt activity. (A) Western blot results showing the changes in phosphatase and tensin homolog (PTEN) and CTMP protein expression levels after NDRG4 knockdown. (B) Relative protein expression levels of CTMP and PTEN represented by the ratio of detected protein to GAPDH protein expression level after NDRG4 knockdown at D0, D2, and D4. (C) Co-immunoprecipitation results of the interaction between NDRG4 and CTMP in vivo. $\mathrm{C} 2 \mathrm{C} 12$ cells were differentiated for 3 days, harvested, and pulled-down by antibodies. Lane 1: The cell lysate (Input) was used as a positive control for Western blotting analysis. Lane 2: Immunoprecipitation results with anti-IgG antibody as a negative control. Lane 3: Immunoprecipitation results with anti-NDRG4 antibody. (D) The subcellular localization of NDRG4 and CTMP demonstrated by immunofluorescence in C2C12 myotubes. C2C12 myotubes were stained with antibodies against NDRG4 (red), CTMP (green), and DAPI (blue). (E) NDRG4-knockdown $\mathrm{C} 2 \mathrm{C} 12$ cells and control cells were lysed and immunoprecipitated with either CTMP antibody or control IgG. Immuno-complexes and input cell lysates were analyzed by Western blotting with anti-pAkt, anti-NDRG4, and anti-CTMP antibodies. 
A

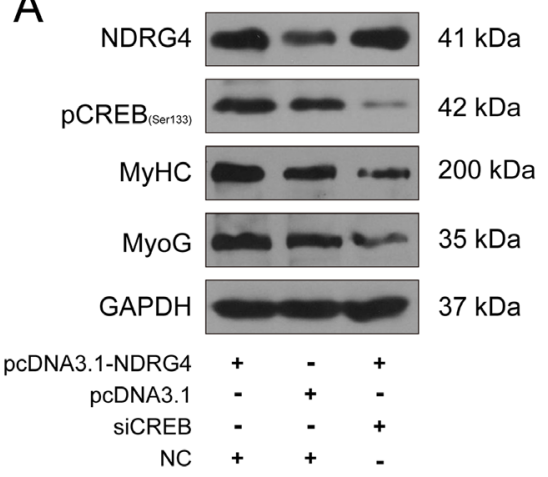

C

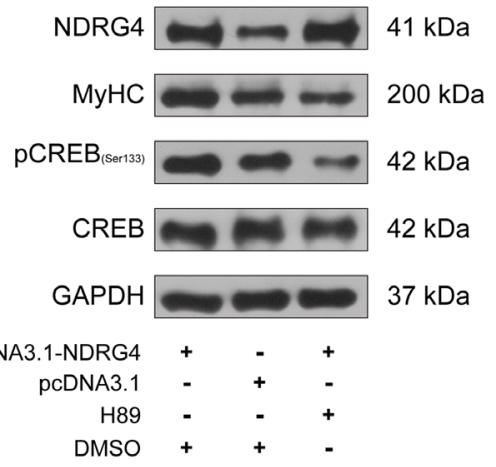

E

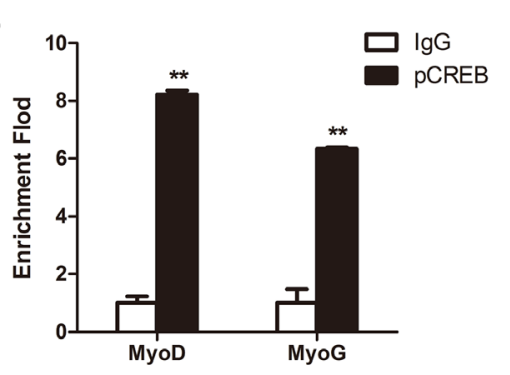

B

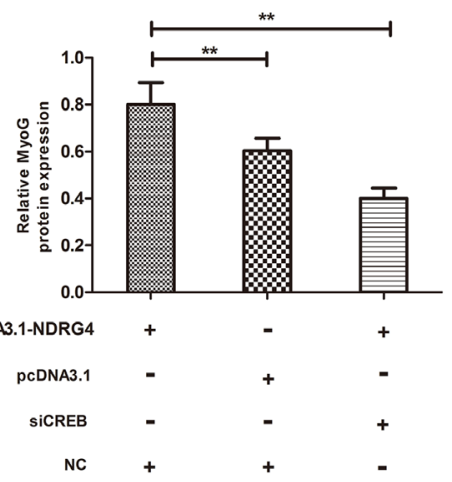

D

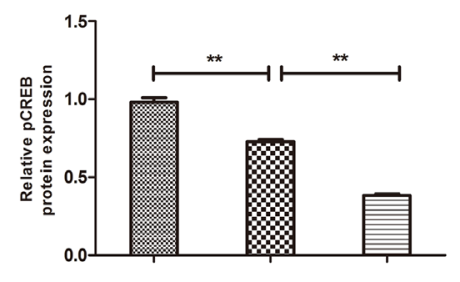

PCDNA3.1-NDRG 4

pcDNA3.1

H89

DMSO

$\mathrm{F}$
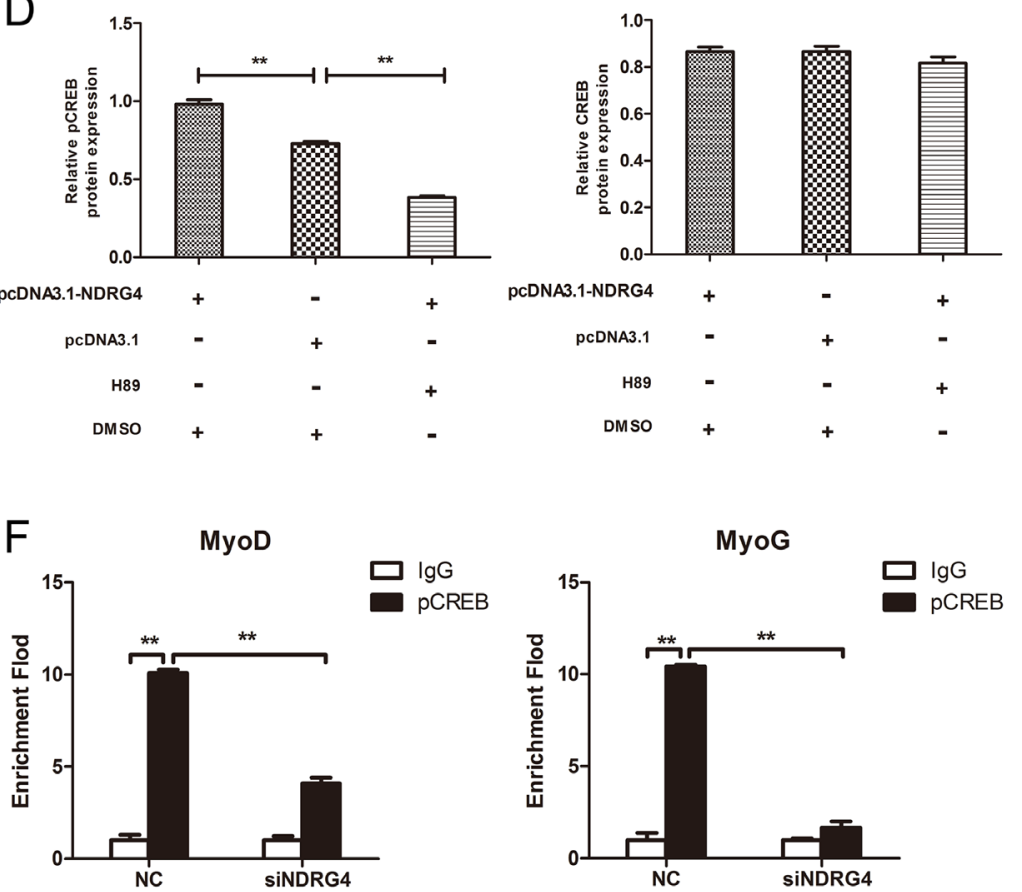

pCDNA3.1-NDRG4

pcDNA3.1

H89

DMSO

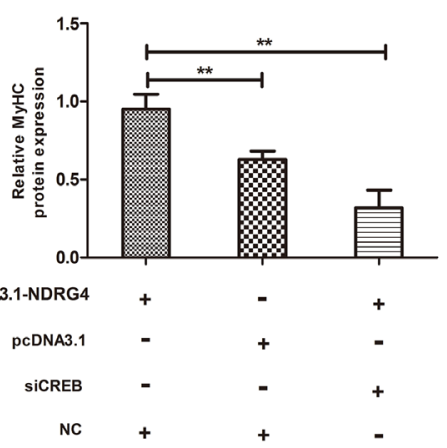

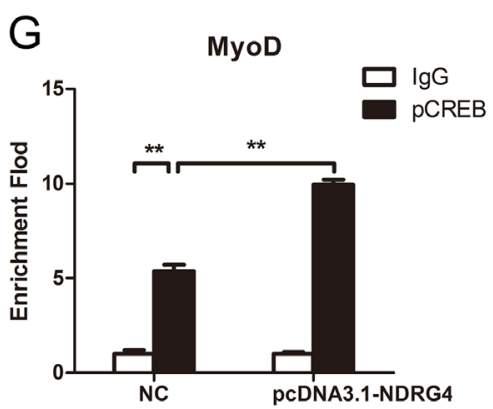

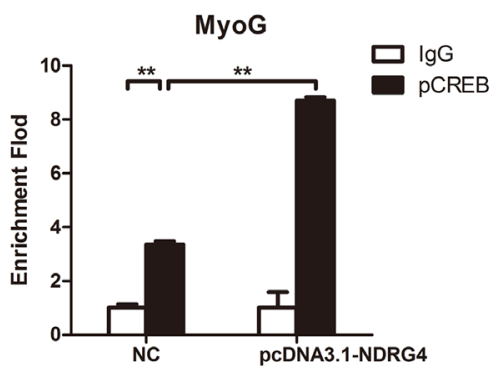

Figure 7: NDRG4 promotes myogenesis by increasing CREB transcription activity. (A) Western blot results of MyoG and MyHC protein expression levels in C2C12 myoblasts after co-transfection with pcDNA3.1-NDRG4 and siCREB and differentiation for 3 days. (B) Relative protein expression levels of $\mathrm{MyoG}$ and MyHC after co-transfection with pcDNA3.1-NDRG4 and siCREB. (C) NDRG4 promotes myogenesis through pCREB. After NDRG4 overexpression, C2C12 cells were treated or not with $10 \mu \mathrm{M} H 89$ and differentiated for 3 days, Protein expression levels of MyHC, CREB and pCREB were detected by western blotting. (D) Relative protein expression levels of CREB and pCREB after NDRG4 overexpression and H89 treatment. (E) Chromatin immunoprecipitation (ChIP) assay results showing the binding of $\mathrm{pCREB}$ to the $\mathrm{MyoD}$ and myogenin promoters in vivo in $\mathrm{C} 2 \mathrm{C} 12$ myoblasts differentiated for 3 days. Normal mouse $\operatorname{IgG}$ was used as the negative control (as below). (F) ChIP assay results showing the effects of NDRG4 knockdown on the binding capacity of pCREB to the MyoD and MyoG promoters in siNDRG4 and NC cells cultured in differentiation medium for 3 days. (G) ChIP assay results showing the effects of NDRG4 overexpression on the binding capacity of pCREB to the MyoD and MyoG promoters in pcDNA3.1 and pcDNA3.1-NDRG4 cells cultured in differentiation medium for 3 days. 
phosphorylation. Previous studies showed that CREB is a transcription factor that binds to cAMP response elements (CRE) in the regulatory region of target genes [36, 38, 39]. To investigate whether CREB directly regulates myogenic genes by binding to their promoter regions, we used the gene-regulation database (http://gene-regulation.com/ pub/programs/alibaba2.html) to predict putative CRElike binding sites. A ChIP assay was performed based on the predicted sites. The results showed that CREB can directly bind the promoter region of $M y o D$ and $M y o G$ genes (Figure 7E). Knockdown of NDRG4 decreased the binding capacity of CREB to the CRE of $M y o D$ and $M y o G$ promoters (Figure 7F). Meanwhile, NDRG4 overexpression had the inverse effect (Figure 7G). These results suggest that NDRG4 strengthens $\mathrm{C} 2 \mathrm{C} 12$ myogenic differentiation by improving CREB transcription activity at the promoters of its target genes.

\section{DISCUSSION}

The NDRG4 protein plays important roles both in vitro and in vivo. Knockdown of the NDRG4 gene dramatically decreases cell viability of glioblastoma cells [21]. The proliferation rate of A10 cells is significantly decreased after overexpression of NDRG4 [40]. Schwann cell proliferation does not significantly differ between $N D R G 4$ morphant embryos and controls throughout development [41]. Here, we first confirmed that $N D R G 4$ is a positive regulator of myogenic differentiation, but $N D R G 4$ has no effects on myoblast proliferation and the cell cycle. These results showed that the effects of the $N D R G 4$ gene on cell phenotype depend on cellular context. In vivo, NDRG4 knockdown in zebrafish embryos causes a marked reduction in proliferative myocytes and results in hypoplastic hearts [20]. Targeted disruption of the

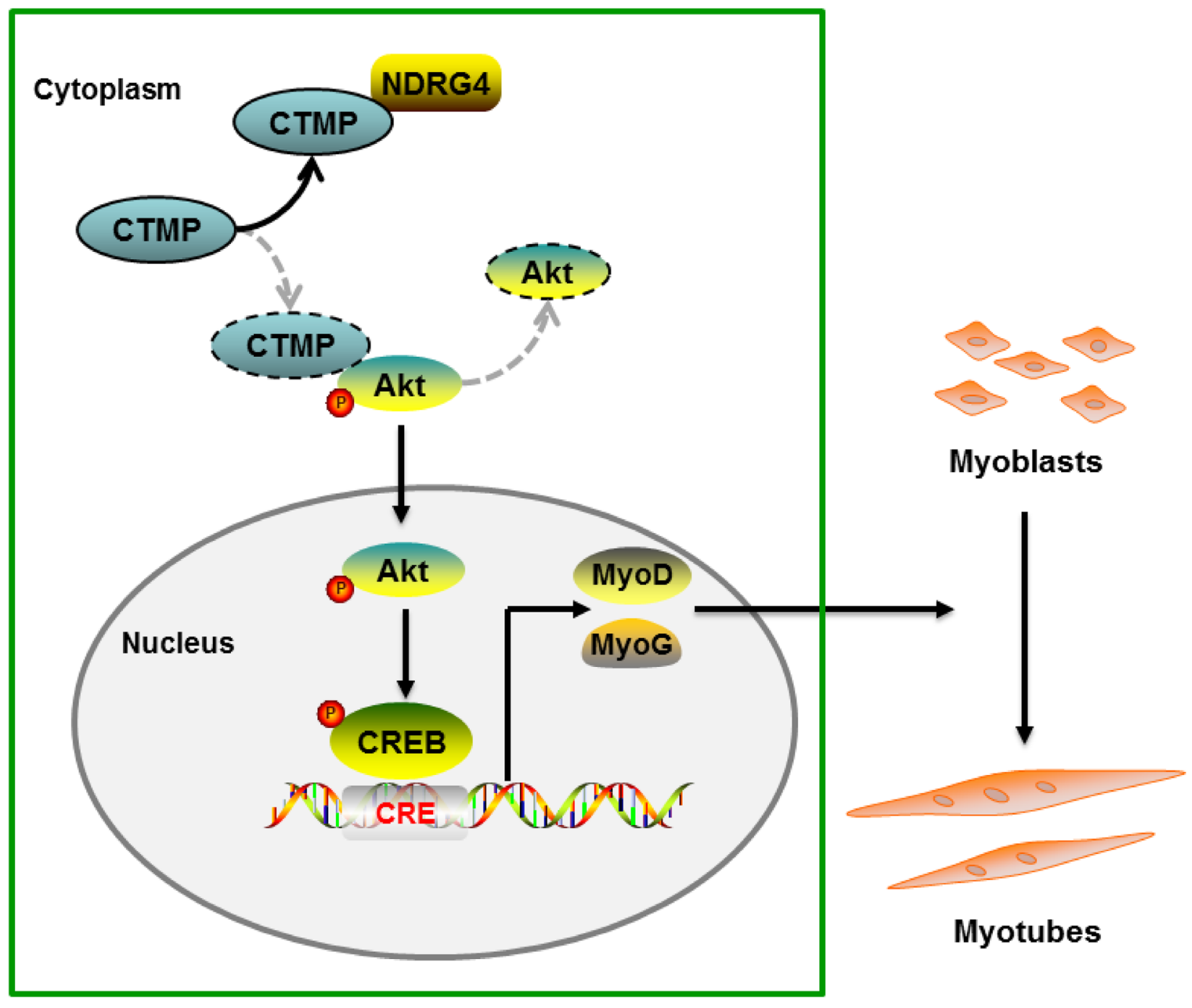

Figure 8: Proposed pathway model for NDRG4 involved in myoblast differentiation. Binding of NDRG4 to CTMP attenuates the inhibitory effect of CTMP on Akt phosphorylation and further promotes the phosphorylation of CREB, leading to increased expression of the $M y o D$ and $M y o G$ genes and promotion of myoblast differentiation. 
NDRG4 gene in mice results in abnormalities in the spleen and thymus, as well as neurological defects [42]. NDRG4 protein-deficient mice exhibit spatial learning deficits and vulnerabilities to cerebral ischemia [19]. Previous studies suggested that NDRG4 was predominantly expressed in the brain and heart of postnatal rats [43]. The function of NDRG4 in skeletal muscle is less well known. We confirmed that expression of NDRG4 increases gradually in the early stages of muscle regeneration. Additionally, expression of pig NDRG4 is significantly higher in embryonic muscle $(35,63$, and $91 \mathrm{dpc})$ than in adult muscle [44]. Therefore, it can be speculated that NDRG4 plays an important role in skeletal muscle determination and early development.

$\mathrm{Akt} / \mathrm{CREB}$ is a classic signaling pathway involved in numerous biological processes. Nobiletin protects the brain from ischemic damage by activating the Akt/ CREB signaling pathway [45]. Combined treatments with Ampakine and brain-derived neurotrophic factor (BDNF) enhance post stroke functional recovery in aged mice via Akt-CREB signaling [46]. Nexrutine $\AA$ inhibits prostate cancer cell proliferation through modulation of Akt and CREB-mediated signaling pathways [47]. During muscle development, Akt is a key regulator of myogenesis [8] and is essential for muscle regeneration [28]. CREB is activated after muscle injury and can promote myogenesis and muscle regeneration [15]. Here, we confirmed that NDRG4 induced Akt and CREB phosphorylation, enhanced the binding capacity of pCREB to CREs in the $M y o D$ and $M y o G$ genes, and promoted myogenic differentiation and myotube formation. Previous studies showed that Akt regulates skeletal muscle hypertrophy in vivo via two signaling pathways [48-50]. One is the mechanistic target of rapamycin (mTOR) pathway, which controls protein synthesis $[51,52]$, and the other is the forkhead box $\mathrm{O}$ (FoxO) pathway, which controls protein degradation [53]. It would be interesting to determine whether NDRG4 affects these signaling pathways.

A previous report showed that interaction between blood vessel epicardial substance (Bves) and NDRG4 influenced epicardial cell movement [35]. NDRG4 directly interacts with p53 in malignant meningioma cells [34]. In this study, we found that NDRG4 interacts with CTMP during C2C12 cell differentiation. CTMP directly binds pAkt and decreases the phosphorylation of Akt [33, 54]. We confirmed that binding of NDRG4 to CTMP weakened the association of CTMP and pAkt, and thereby altered the phosphorylation of Akt. Based on our results, we speculate that increased NDRG4 during myogenesis antagonizes the inhibitory effect of CTMP on Akt phosphorylation. CTMP protein is comprised of a catalytically active hotdog-fold acyl-CoA thioesterase domain and an $\mathrm{N}$-terminal domain, and the N-terminal domain is partially composed of an irregular and flexible secondary structure, reminiscent of a protein-binding domain [55]. Therefore, we assume that NDRG4 competes with Akt to bind to the N-terminal domain of CTMP. The NDRG4 protein has NDR- and $\alpha / \beta$ hydrolase-fold motifs. Additionally, it also contains one phosphorylation site and seventeen acetylation sites [16]. Beyond that, little is known about the relationship between NDRG4 protein structure and its biological function. Therefore, further investigations are needed to clarify which domain of NDRG4 is necessary and sufficient for its function as a positive regulator during myogenic differentiation.

In summary, we showed that NDRG4 promotes myogenic differentiation through the Akt/CREB signaling pathway. The mechanism of action is the binding of NDRG4 to CTMP, which abates the interaction of CTMP and pAkt, increasing the phosphorylation level of Akt (Figure 8). Our results suggest that NDRG4 plays an important role in regulation of myogenesis during skeletal muscle development.

\section{MATERIALS AND METHODS}

\section{Murine model of CTX-induced muscle injury}

Muscle injury was performed by injecting $100 \mu \mathrm{L}$ of $10 \mu \mathrm{M}$ CTX (Sigma-Aldrich, St. Louis, MO, USA) into the hindlimb muscles of 8 -week-old C57BL/6 mice. Muscles were harvested at days $0,1,2,3,5$, and 8 after injection for RNA extraction.

\section{Cell culture and differentiation of $\mathrm{C} 2 \mathrm{C} 12$ myoblasts}

Mouse C2C12 cells were cultured in growth medium (GM) (Dulbecco's modified Eagle medium [DMEM]; Hyclone, Marlborough, MA, USA) supplemented with 10\% fetal bovine serum (Gibco, Australia) and were maintained at $37^{\circ} \mathrm{C}$ in a $5 \% \mathrm{CO}_{2}$ incubator. For differentiation experiments, when cells reached $80-90 \%$ confluence, the medium was changed to diffrentiation medium (DM) (DMEM supplemented with 2\% horse serum [Gibco]). Differentiation medium was replaced every $24 \mathrm{~h}$.

\section{Plasmids, small interfering RNAs (siRNAs), and transfection}

For NDRG4 expression vector, mouse NDRG4 CDS was amplified by NDRG4-F (5'-CCCAAGCTT ATGCCGGAGTGCTGGGATGG-3') and NDRG4-R (5'-GGAATTCTCAGCAGGACACCTCCATGG-3') primers and inserted into pcDNA3.1 vector. NDRG4 siRNAs (S: GAUGCUGGUAGUCGGAGAUAATT; A: UUAUCUCCGACUACCAGCAUCTT) and CREB SiRNAs (S: GGACCUUUA CUGCCACAAATT; A: UUUGUGGCAGUAAAGGUCCTT) were synthesized by GenePharma (Shanghai, China). C2C12 cells were transfected with plasmids or siRNAs using Lipofectamine 
2000 transfection reagent (Invitrogen, Carlsbad, CA, USA) according to the manufacturer's instructions. Opti-MEM I Reduced Serum Medium (Gibco) was used to dilute Lipofectamine 2000 and nucleic acids. All transfections were performed in triplicate for each experiment.

\section{Cell proliferation analysis}

C2C12 cells were seeded on a 16-well E-Plate at 5000 cells per well and allowed to grow for $12-24 \mathrm{~h}$. The cells were transfected with NDRG4 expression vector or siNDRG4 when the cell index reached about 1.0 in at least three wells per treatment. Cell growth and proliferation were monitored by an xCELLigence RTCA DP instrument (Roche Applied Science, Penzberg, Upper Bavaria, Germany).

The cell cycle was analyzed by flow cytometry. Briefly, $48 \mathrm{~h}$ after transfection, the $\mathrm{C} 2 \mathrm{C} 12$ cells were fixed in $70 \%(\mathrm{v} / \mathrm{v})$ ethanol overnight at $-20^{\circ} \mathrm{C}$. Following incubation in $50 \mathrm{mg} / \mathrm{ml}$ propidium iodide (PI) for 30 min at $4^{\circ} \mathrm{C}$, cell cycle profiling was performed using a FACSCalibur Flow Cytometer (Becton Dickinson, Franklin Lakes, NJ, USA) and the data were analyzed using ModFit software (Verity Software House).

\section{RNA isolation and quantitative real-time PCR (qRT-PCR)}

Total RNA from $\mathrm{C} 2 \mathrm{C} 12$ myoblasts and skeletal muscle was extracted using an HP Total RNA Kit (Omega Bio-tek, Norcross, GA, USA) and treated with DNase I (Thermo Fisher Scientific, Waltham, MA, USA). The concentration and quality of RNA were assessed using a NanoDrop 2000 (Thermo Fisher Scientific) and agarose gel electrophoresis. Total RNA was reverse transcribed using the PrimeScript RT reagent kit with genomic DNA eraser (Takara, Japan). The qRT-PCR reaction was performed in a LightCycler 480 II (Roche, Basel, Switzerland) system using the SYBR ${ }^{\circ}$ Green Real-time PCR Master Mix (Toyobo, Japan). The Ct $\left(2^{-\Delta \Delta C t}\right)$ method was used to analyze the relative gene expression data following the literature.

\section{Western blotting}

Cells were lysed in RIPA lysis buffer (Beyotime, Jiangsu, China) according to the manufacturer's instructions. After being mixed with sodium dodecyl sulfate (SDS) sample buffer and boiled for $10 \mathrm{~min}$, denatured protein samples were separated by $10 \%$ SDSpolyacrylamide gel electrophoresis and electrotransferred onto polyvinylidene fluoride membranes (Millipore, Billerica, MA, USA) using a Mini Trans-Blot Cell system (Bio-Rad, Hercules, CA, USA). The membranes were blocked with $5 \%$ non-fat milk for $2 \mathrm{~h}$ and incubated overnight at $4^{\circ} \mathrm{C}$ with primary antibodies against
NDRG4 (Santa Cruz Biotechnology, Santa Cruz, CA, USA; sc-166,917, 1:200 dilution), MyoG (Santa Cruz Biotechnology; sc-12,732, 1:200 dilution), MyHC (Santa Cruz Biotechnology; sc-376,157, 1:3000 dilution), CREB (Cell Signaling Technology, Danvers, MA, USA; 48H2, 1:2000 dilution), GAPDH (Boster, China; BM0627, 1:1000 dilution), MyoD (Santa Cruz Biotechnology; sc377,186, 1:200 dilution), Akt (Cell Signaling Technology, Danvers, MA, USA; 40D4, 1:2000 dilution), pAkt (Cell Signaling Technology, Danvers, MA, USA; D9E, 1:1000 dilution), carboxyl-terminal modulator protein (CTMP) (Santa Cruz Biotechnology, CA, sc-390,353 1:200 dilution), PTEN (Cell Signaling Technology, Danvers, MA, USA; Y184, 1:1000 dilution), and phospho-CREB at ser133 rabbit monoclonal (Cell Signaling Technology, Danvers, MA, USA; 87G3), followed by incubation with goat anti-mouse IgG-horseradish peroxidase (HRP) (Santa Cruz Biotechnology; sc-2005, 1:3000 dilution) and goat anti-rabbit IgG-HRP (Santa Cruz Biotechnology; sc-2004, 1:3000 dilution) secondary antibodies for $1 \mathrm{~h}$ at room temperature. Immune complexes were detected using the Clarity ${ }^{\mathrm{TM}}$ and Clarity $\mathrm{Max}^{\mathrm{TM}}$ Western ECL Blotting Substrates (BIORAD, California, USA). The band signal intensities were determined using ImageJ software. Western blots were quantified by normalized the band density of phosphorylated proteins to their total protein level, whilst all other proteins were quantified by normalized the band to GAPDH.

\section{Immunofluorescence}

Immunofluorescence was performed as previously described [36]. The primary antibodies included mouse anti-MyHC (1:100 dilution) and NDRG4 (1:50 dilution). The secondary antibodies included anti-rabbit FITC-IgG (Beyotime, Jiangsu, China) and anti-mouse Cy3-IgG (Beyotime). Myoblast fusion was analyzed by calculating numbers of nuclei in MyHC-positive cells. The number of nuclei in individual myotubes was counted for 50-100 myotubes in 8 random fields. MyHC-positive cells were grouped into: those with one nuclei, those with 2-5 nuclei, and those with $\geq 6$ nuclei. The percentages of nuclei in these three groups were expressed as percentages of total nuclei in MyHC-positive cells.

\section{Co-immunoprecipitation assay}

C2C12 myoblasts were seeded in 10-cm dishes and differentiated for 3 days. Cells were lysed in $1 \mathrm{ml}$ lysis buffer (Sangon, Shanghai, China) and protease inhibitor (Sangon). The lysate was centrifuged to remove insoluble components and incubated with either antiNDRG4 antibody, anti-CTMP antibody, or IgG antibody (Beyotime) overnight at $4^{\circ} \mathrm{C}$. The immune complexes were then incubated with Protein $\mathrm{A}+\mathrm{G}$ agarose beads (Beyotime) for $1.5 \mathrm{~h}$. The beads were washed five times 
with lysis buffer. The proteins were analyzed by Western blotting as described above.

\section{Chromatin immunoprecipitation (ChIP) assay}

ChIP assays were performed using the ChIP Assay Kit (Beyotime). Briefly, after crosslinking the chromatin with $1 \%$ formaldehyde at $37^{\circ} \mathrm{C}$ for $20 \mathrm{~min}$ and neutralizing with glycine for $5 \mathrm{~min}$ at room temperature, $\mathrm{C} 2 \mathrm{C} 12$ myoblasts were washed with cold phosphate-buffered saline, scraped, and collected. Nuclear lysates were sonicated 15 times for $10 \mathrm{~s}$ at 10 -s intervals on ice using a Sonics VCX 130 (Sonics, USA). The chromatin complex was immunoprecipitated at $4^{\circ} \mathrm{C}$ overnight with pCREB (Ser133) rabbit antibodies using phenol/chloroform. Real-time PCR was performed to analyze the DNA fragments. The primers were MyoD-cF (forward primer, 5'-CCCAGATGGAGAATGACCAAA-3'), MyoD-cR (reverse primer, 5'- AAGGCTACGGGACAATGAAAG-3') and MyoG-cF (forward primer, 5'-TCAAAGAAGCTGTAGAAACCCAA-3'), MyoG-cR (reverse primer, 5'-TCAGCAG CACCTTAAACCATAC-3'). According to the ChIP analysis manual (Thermofisher scientific), Relative enrichment is calculated as the amount of amplified DNA normalized to input and relative to values obtained after normal $\mathrm{IgG}$ immunoprecipitation.

\section{Statistical analysis}

All results are presented as the means \pm standard error. The data were accumulated from at least three independent experiments. Two-tailed Student's $t$-tests were used for $P$-value calculations.

\section{ACKNOWLEDGMENTS AND FUNDING}

We thank Shanshan Wang and Wei Lv for their critical comments and Jianjun Jin for performing the murine model of CTX-induced muscle injury. This study was supported by the National Project for Breeding of Transgenic Pig (2016ZX08006-002), the National High Technology Development Project of China (2013AA102502), the Agricultural Innovation Fund of Hubei Province and the Fundamental Research Funds for the Central Universities (Grant nos. 2662015PY160).

\section{CONFLICTS OF INTEREST}

The authors declare no conflicts of interest.

\section{REFERENCES}

1. Blau HM, Pavlath GK, Hardeman EC, Chiu CP, Silberstein L, Webster SG, Miller SC, Webster C. Plasticity of the differentiated state. Science. 1985; 230: 758-66.
2. Berkes CA, Tapscott SJ. MyoD and the transcriptional control of myogenesis. Semin Cell Dev Biol. 2005; 16: 585-95.

3. Apponi LH, Corbett AH, Pavlath GK. RNA-binding proteins and gene regulation in myogenesis. Trends Pharmacol Sci. 2011; 32: 652-8.

4. Rudnicki MA, Schnegelsberg PN, Stead RH, Braun T, Arnold HH, Jaenisch R. MyoD or Myf-5 is required for the formation of skeletal muscle. Cell. 1993; 75: 1351-9.

5. Tapscott SJ, Davis RL, Thayer MJ, Cheng PF, Weintraub $\mathrm{H}$, Lassar AB. MyoD1: a nuclear phosphoprotein requiring a Myc homology region to convert fibroblasts to myoblasts. Science. 1988; 242: 405-11.

6. Choi J, Costa ML, Mermelstein CS, Chagas C, Holtzer $\mathrm{S}$, Holtzer H. MyoD converts primary dermal fibroblasts, chondroblasts, smooth muscle, and retinal pigmented epithelial cells into striated mononucleated myoblasts and multinucleated myotubes. Proc Natl Acad Sci U S A. 1990; 87: 7988-92.

7. Mastroyiannopoulos NP, Nicolaou P, Anayasa M, Uney JB, Phylactou LA. Down-regulation of myogenin can reverse terminal muscle cell differentiation. PLos One. 2012; 7.

8. Jiang BH, Aoki M, Zheng JZ, Li J, Vogt PK. Myogenic signaling of phosphatidylinositol 3-kinase requires the serine-threonine kinase Akt/protein kinase B. Proc Natl Acad Sci U S A. 1999; 96: 2077-81.

9. Fujio Y, Guo K, Mano T, Mitsuuchi Y, Testa JR, Walsh K. Cell cycle withdrawal promotes myogenic induction of Akt, a positive modulator of myocyte survival. Mol Cell Biol. 1999; 19: 5073-82.

10. Tureckova J, Wilson EM, Cappalonga JL, Rotwein P. Insulin-like growth factor-mediated muscle differentiation: collaboration between phosphatidylinositol 3-kinase-Aktsignaling pathways and myogenin. J Biol Chem. 2001; 276: 39264-70.

11. Rotwein P, Wilson EM. Distinct actions of Akt1 and Akt2 in skeletal muscle differentiation. J Cell Physiol. 2009; 219: 503-11.

12. Li XY, Zhan XR, Liu XM, Wang XC. CREB is a regulatory target for the protein kinase Akt/PKB in the differentiation of pancreatic ductal cells into islet beta-cells mediated by hepatocyte growth factor. Biochem Biophys Res Commun. 2011; 404: 711-6.

13. Du K, Montminy M. CREB is a regulatory target for the protein kinase Akt/PKB. J Biol Chem. 1998; 273: 32377-9.

14. Daniel P, Filiz G, Brown DV, Hollande F, Gonzales M, D'Abaco G, Papalexis N, Phillips WA, Malaterre J, Ramsay RG, Mantamadiotis T. Selective CREB-dependent cyclin expression mediated by the PI3K and MAPK pathways supports glioma cell proliferation. Oncogenesis. 2014; 3: e108.

15. Stewart R, Flechner L, Montminy M, Berdeaux R. CREB is activated by muscle injury and promotes muscle regeneration. PLoS One. 2011; 6 . 
16. Melotte V, Qu X, Ongenaert M, van Criekinge W, de Bruine AP, Baldwin HS, van Engeland M. The N-myc downstream regulated gene (NDRG) family: diverse functions, multiple applications. FASEB J. 2010; 24: 4153-66.

17. Brailoiu GC, Dun SL, Mizuo K, Brailoiu E, Yang J, Chang JK, Dun NJ. Smooth muscle-associated protein 8: distribution and biological activity in the rat brain. $\mathrm{J}$ Neurosci Res. 2007; 85: 1789-96.

18. Zhou RH, Kokame K, Tsukamoto Y, Yutani C, Kato H, Miyata T. Characterization of the human NDRG gene family: a newly identified member, NDRG4, is specifically expressed in brain and heart. Genomics. 2001; 73: 86-97.

19. Yamamoto H, Kokame K, Okuda T, Nakajo Y, Yanamoto H, Miyata T. NDRG4 protein-deficient mice exhibit spatial learning deficits and vulnerabilities to cerebral ischemia. J Biol Chem. 2011; 286: 26158-65.

20. Qu XH, Jia HB, Garrity DM, Tompkins K, Batts L, Appel $\mathrm{B}$, Zhong TP, Baldwin HS. ndrg4 is required for normal myocyte proliferation during early cardiac development in zebrafish. Dev Biol. 2008; 317: 486-96.

21. Schilling SH, Hjelmeland AB, Radiloff DR, Liu IM, Wakeman TP, Fielhauer JR, Foster EH, Lathia JD, Rich JN, Wang XF, Datto MB. NDRG4 is required for cell cycle progression and survival in glioblastoma cells. J Biol Chem. 2009; 284: 25160-9.

22. Kotipatruni RP, Ferraro DJ, Ren $X$, Vanderwaal RP, Thotala DK, Hallahan DE, Jaboin JJ. NDRG4, the N-Myc downstream regulated gene, is important for cell survival, tumor invasion and angiogenesis in meningiomas. Integr Biol. 2012; 4: 1185-97.

23. Ding WC, Zhang J, Yoon JG, Shi DY, Foltz G, Lin BY. NDRG4 is downregulated in glioblastoma and inhibits cell proliferation. OMICS. 2012; 16: 263-7.

24. Yang Q, Gu Y, Zhang X, Wang JM, He YP, Shi Y, Sun ZG, Shi HJ, Wang J. Uterine expression of NDRG4 is induced by estrogen and up-regulated during embryo implantation process in mice. PLoS One. 2016; 11.

25. Tomczak KK, Marinescu VD, Ramoni MF, Sanoudou D, Montanaro F, Han M, Kunkel LM, Kohane IS, Beggs $\mathrm{AH}$. Expression profiling and identification of novel genes involved in myogenic differentiation. FASEB J. 2003; 17: 403-5.

26. Lukjanenko L, Brachat S, Pierrel E, Lach-Trifilieff E, Feige $\mathrm{JN}$. Genomic profiling reveals that transient adipogenic activation is a hallmark of mouse models of skeletal muscle regeneration. PLoS One. 2013; 8.

27. Magenta A, Cenciarelli C, De Santa F, Fuschi P, Martelli F, Caruso M, Felsani A. MyoD stimulates RB promoter activity via the CREB/p300 nuclear transduction pathway. Mol Cell Biol. 2003; 23: 2893-906.

28. Waldemer-Streyer RJ, Chen J. Myocyte-derived Tnfsf14 is a survival factor necessary for myoblast differentiation and skeletal muscle regeneration. Cell Death Dis. 2015; 6: e2026.
29. Lawlor MA, Alessi DR. PKB/Akt: a key mediator of cell proliferation, survival and insulin responses? J Cell Sci. 2001; 114: 2903-10.

30. Manning BD, Cantley LC. AKT/PKB signaling: navigating downstream. Cell. 2007; 129: 1261-74.

31. Frost RA, Lang $\mathrm{CH}$. Protein kinase B/Akt: a nexus of growth factor and cytokine signaling in determining muscle mass. J Appl Physiol (1985). 2007; 103: 378-87.

32. Stambolic V, Suzuki A, de la Pompa JL, Brothers GM, Mirtsos C, Sasaki T, Ruland J, Penninger JM, Siderovski DP, Mak TW. Negative regulation of PKB/Akt-dependent cell survival by the tumor suppressor PTEN. Cell. 1998; 95: 29-39.

33. Maira SM, Galetic I, Brazil DP, Kaech S, Ingley E, Thelen M, Hemmings BA. Carboxyl-terminal modulator protein (CTMP), a negative regulator of $\mathrm{PKB} / \mathrm{Akt}$ and $\mathrm{v}$-Akt at the plasma membrane. Science. 2001; 294: 374-80.

34. Kotipatruni RP, Ren X, Thotala D, Jaboin JJ. NDRG4 is a novel oncogenic protein and p53 associated regulator of apoptosis in malignant meningioma cells. Oncotarget. 2015; 6: 17594-604. https://doi.org/10.18632/oncotarget.4009.

35. Benesh EC, Miller PM, Pfaltzgraff ER, Grega-Larson NE, Hager HA, Sung BH, Qu XH, Baldwin HS, Weaver AM, Bader DM. Bves and NDRG4 regulate directional epicardial cell migration through autocrine extracellular matrix deposition. Mol Biol Cell. 2013; 24: 3496-510.

36. Zhang Y, Li W, Zhu M, Li Y, Xu Z, Zuo B. FHL3 differentially regulates the expression of $\mathrm{MyHC}$ isoforms through interactions with MyoD and pCREB. Cell Signal. 2016; 28: 60-73.

37. Wang B, Zhu L, Sui S, Sun C, Jiang H, Ren D. Cilostazol induces mitochondrial fatty acid $\beta$-oxidation in $\mathrm{C} 2 \mathrm{C} 12$ myotubes. Biochem Biophys Res Commun. 2014; 447: 441-5.

38. Zhang X, Odom DT, Koo SH, Conkright MD, Canettieri G, Best J, Chen H, Jenner R, Herbolsheimer E, Jacobsen E, Kadam S, Ecker JR, Emerson B, et al. Genome-wide analysis of cAMP-response element binding protein occupancy, phosphorylation, and target gene activation in human tissues. Proc Natl Acad Sci U S A. 2005; 102: 4459-64.

39. Mayr B, Montminy M. Transcriptional regulation by the phosphorylation-dependent factor CREB. Nat Rev Mol Cell Biol. 2001; 2: 599-609.

40. Nishimoto S, Tawara J, Toyoda H, Kitamura K, Komurasaki T. A novel homocysteine-responsive gene, smap8, modulates mitogenesis in rat vascular smooth muscle cells. Eur J Biochem. 2003; 270: 2521-31.

41. Fontenas L, Chambraud B, Tawk M. Neuronal ndrg4 is essential for Nodes of Ranvier organization and myelination in zebrafish. Glia. 2015; 63: E205-E6.

42. Qu X, Li J, Baldwin HS. Postnatal lethality and abnormal development of foregut and spleen in Ndrg4 mutant mice. Biochem Biophys Res Commun. 2016; 470: 613-9. 
43. Yamauchi Y, Hongo S, Ohashi T, Shioda S, Zhou C, Nakai Y, Nishinaka N, Takahashi R, Takeda F, Takeda M. Molecular cloning and characterization of a novel developmentally regulated gene, Bdm1, showing predominant expression in postnatal rat brain. Brain Res Mol Brain Res. 1999; 68: 149-58.

44. Siengdee P, Trakooljul N, Murani E, Schwerin M, Wimmers K, Ponsuksili S. Transcriptional profiling and miRNAdependent regulatory network analysis of longissimus dorsi muscle during prenatal and adult stages in two distinct pig breeds. Anim Genet. 2013; 44: 398-407.

45. Zhang L, Zhao H, Zhang X, Chen L, Zhao X, Bai X, Zhang J. Nobiletin protects against cerebral ischemia via activating the p-Akt, p-CREB, BDNF and Bcl-2 pathway and ameliorating BBB permeability in rat. Brain Res Bull. 2013; 96: 45-53.

46. Clarkson AN, Parker K, Nilsson M, Walker FR, Gowing EK. Combined ampakine and BDNF treatments enhance poststroke functional recovery in aged mice via AKT-CREB signaling. J Cereb Blood Flow Metab. 2015; 35: 1272-9.

47. Kumar AP, Bhaskaran S, Ganapathy M, Crosby K, Davis MD, Kochunov P, Schoolfield J, Yeh IT, Troyer DA, Ghosh R. Akt/cAMP-responsive element binding protein/cyclin D1 network: a novel target for prostate cancer inhibition in transgenic adenocarcinoma of mouse prostate model mediated by Nexrutine, a Phellodendron amurense bark extract. Clin Cancer Res. 2007; 13: 2784-94.

48. Glass DJ. Signalling pathways that mediate skeletal muscle hypertrophy and atrophy. Nat Cell Biol. 2003; 5: 87-90.
49. Rodriguez J, Vernus B, Chelh I, Cassar-Malek I, Gabillard JC, Sassi AH, Seiliez I, Picard B, Bonnieu A. Myostatin and the skeletal muscle atrophy and hypertrophy signaling pathways. Cell Mol Life Sci. 2014; 71: 4361-71.

50. Lai KM, Gonzalez M, Poueymirou WT, Kline WO, Na E, Zlotchenko E, Stitt TN, Economides AN, Yancopoulos GD, Glass DJ. Conditional activation of akt in adult skeletal muscle induces rapid hypertrophy. Mol Cell Biol. 2004; 24: 9295-304.

51. Bolster DR, Jefferson LS, Kimball SR. Regulation of protein synthesis associated with skeletal muscle hypertrophy by insulin-, amino acid- and exercise-induced signalling. Proc Nutr Soc. 2004; 63: 351-6.

52. Miyazaki M, Esser KA. Cellular mechanisms regulating protein synthesis and skeletal muscle hypertrophy in animals. J Appl Physiol (1985). 2009; 106: 1367-73.

53. Sandri M, Sandri C, Gilbert A, Skurk C, Calabria E, Picard A, Walsh K, Schiaffino S, Lecker SH, Goldberg AL. Foxo transcription factors induce the atrophy-related ubiquitin ligase atrogin-1 and cause skeletal muscle atrophy. Cell. 2004; 117: 399-412.

54. Zhao SF, Fu JD, Liu F, Rastogi R, Zhang JL, Zhao YL. Small interfering RNA directed against CTMP reduces acute traumatic brain injury in a mouse model by activating Akt. Neurol Res. 2014; 36: 483-90.

55. Zhao H, Lim K, Choudry A, Latham JA, Pathak MC, Dominguez D, Luo L, Herzberg O, Dunaway-Mariano D. Correlation of structure and function in the human hotdogfold enzyme hTHEM4. Biochemistry. 2012; 51: 6490-2. 